\title{
NIETZSCHE E A TEORIA DO CONHECIMENTO
}

Francisco de Paula Santana de Jesus ${ }^{I}$

Resumo: o presente trabalho tem como objetivo descrever e investigar a crítica nietzschiana a Teoria do Conhecimento e em que consiste o conhecimento para o filósofo. Com isso, evidenciamos que o método genealógico desenvolvido por Nietzsche viabiliza não somente solapar as posturas dogmáticas em relação ao conhecimento, mas também lançar bases para uma outra concepção de conhecimento onde o caráter perspectivístico da efetividade seja posto em destaque, possibilitando um permanente trabalho de investigação das condições de possibilidade de constituição das instâncias avaliativas através das quais o ser humano se orienta.

Palavras-chave: Nietzsche. Teoria do Conhecimento. Filosofia.

Abstract: The present work aims to describe and investigate the Nietzschean criticism of the Theory of Knowledge and what constitutes knowledge for the philosopher. With this, we show that the genealogical method developed by Nietzsche makes possible not only to undermine the dogmatic postures in relation to knowledge, but also to lay the foundations for another conception of knowledge where the perspective of effectiveness is highlighted, allowing a permanent research work the conditions for the possibility of constituting the evaluative bodies through which human beings orient themselves.

Keywords: Nietzsche. Theory of Knowledge. Philosophy.

\footnotetext{
${ }^{1}$ Possui Licenciatura em Filosofia pela Faculdade São Bento da Bahia. Cursa Bacharelado em Psicologia no Centro Universitário Jorge Amado. Atua como professor de Filosofia na rede particular de ensino em Salvador. Currículo Lattes: http://lattes.cnpq.br/8541124782527338.
} 
Nietzsche é considerado um dos maiores críticos da modernidade. Nesse sentido, não seria diferente em relação às doutrinas e disciplinas filosóficas de destaque nesse período. Entre elas se encontra a Teoria do Conhecimento (Erkenntnistheorie) e sua pretensão em estabelecer por definitivo em que se fundaria a validade do conhecimento. Contudo, como o binômio negação-afirmação é constitutivo da filosofia nietzschiana, sua crítica da Teoria do Conhecimento dos modernos implica na proposta de uma nova concepção de conhecimento, cujas bases não se encontrariam mais na suposição nas oposições sujeito-objeto (onde o primeiro elemento seria considerado "ponto arquimediano" dotado de faculdades capazes de enquadrar o segundo através de categorias que lhes são constitutivas), mundo verdadeiromundo aparente, verdade-mentira etc.

Nesse sentido, o presente trabalho tem como objetivo descrever e investigar a crítica nietzschiana a Teoria do Conhecimento. Para tanto, utilizaremos as obras do último período produtivo do filósofo. Outrossim, é importante salientar que, no caso de Nietzsche, considerar em que medida sua filosofia se relaciona com determinadas questões do contexto social e pessoal em que foi produzida contribuí para vislumbrarmos o desenvolvimento interno de sua filosofia. Posto isso, para orientar as linhas que se seguem, cabe-nos perguntar: em que medida é possível aventar uma teoria do conhecimento nietzschiana em sua crítica a Teoria do Conhecimento tradicional? E ainda, o que é o conhecimento para Nietzsche? Com isso, à guisa de introdução, faz-se necessário abordar, mesmo que brevemente, o que seria a Erkenntnistheorie dos modernos.

A Teoria do Conhecimento consiste, grosso modo, numa disciplina filosófica preocupada em investigar a origem, a possibilidade e a essência do conhecimento (HESSEN, 1978). Tal disciplina obteve especial destaque entre os filósofos modernos, fossem eles defensores de um ceticismo moderado, tal como Hume, ou de um dogmatismo especial, como Descartes ou Spinoza ${ }^{2}$; em ambos os casos, todos estavam mais ou menos preocupados sobretudo com questões de método. O ápice do desenvolvimento dessa disciplina estaria na crítica kantiana cujo objetivo seria precisamente estabelecer os limites das faculdades gnosiológicas, bem como as condições de possibilidade para o conhecimento.

Desse modo, é possível dizer que, para os modernos, a verdade verdadeiramente veraz, ou seja, o conhecimento objetivo e universal, porque necessário e suficiente - e isto é válido sobretudo para os dogmáticos —, seria resultado do proceder da razão metodicamente

\footnotetext{
${ }^{2}$ Aqui nós seguimos a indicação de Hessen onde o dogmatismo e o ceticismo dos modernos seria especialmente relacionado a possibilidade da Metafísica. Johannes Hessen. Teoria do Conhecimento. 7 ed. tradução Antônio Correia. Coimbra, Armênio Amado, 1978, p. 39 e 42.
} 
orientada porque livre da arbitrariedade intrínseca a Natureza. Em outras palavras, o conhecimento estaria na justa interrelação de sujeito e objeto. O intelecto dotado de estruturas lógicas seria capaz de enquadrar/apreender aquilo que há de essencial nos fenômenos.

Contudo, a falência dos grandes sistemas metafísicos, o desenvolvimento das ciências e mesmo o surgimento de novas áreas do saber científico, bem como transformações nas estruturas das sociedades europeias ainda no século XIX, levaram os filósofos a buscar novas formas de racionalidade capazes de oferecer respostas que não estivessem ancoradas nas alturas. Em outras palavras, a filosofia da segunda metade do Oitocentos foi marcada pelo desejo de "um novo relacionamento entre razão e experiência" (NUNES, 2004, p. 21). É nesse contexto que Friedrich W. Nietzsche se insere e lança suas críticas mordazes contra as pretensões universalistas em relação ao conhecimento.

Em um longo fragmento póstumo, Nietzsche questiona a relação sujeito-objeto existente na Teoria do Conhecimento. Para o filósofo, "não há nem 'espírito', nem entendimento, nem pensar, nem consciência, nem alma, nem vontade, nem verdade" (NIETZSCHE, 2002, p. 79). Isto se deve a concepção fundamental de vontade de poder (Wille zur Macht) na qual a realidade teria um caráter relacional. Ou, em suas palavras, "o mundo definido e designado conforme o seu 'caráter inteligível' — seria justamente 'vontade de poder', e nada mais" (NIETZSCHE, 2005, p. 40). Com isso, portanto, as oposições que outrora orientavam as investigações filosóficas perdem seu significado. Nesse sentido, Roberto Machado salienta que, "uma crítica interna da faculdade do conhecimento é algo sem sentido" (MACHADO, 2017, p. 74). Pois se tudo se resume a vontade de poder, não é possível falar em sujeito, faculdades cognitivas e tampouco em um objeto definido (o real enquanto algo fixo) para o qual elas se voltariam.

Essa concepção começa a ganhar corpo nas obras do filósofo a partir do Zaratustra, e ainda mais no período em que redige Além de Bem e Mal, ou seja, a partir de 1885. Rüdiger Safranski afirma que, ao entrar em contato "com alguns axiomas retirados do darwinismo biológico e da física de sua época" (SAFRANSKI, 2017, p. 267), nas figuras da seleção natural e do princípio de conservação de energia, Nietzsche elabora uma teoria que em seu nível macro seria capaz de conferir uma explicado não-dualista ao mundo, mas também, em seu nível micro, permitiria uma abordagem naturalista dos processos cognitivos, por exemplo. Assim, continua o autor, ao passo que Nietzsche afirma ser o mundo uma totalidade limitada de forças que se opõem e estabelecem hierarquias sempre moventes, "a vida individual" 
igualmente "é força, energia" que, enquanto domínio do orgânico, seria capaz de percebe-se enquanto perspectiva (SAFRANSKI, 2017, p. 267).

Para Nietzsche, a questão da Teoria do Conhecimento se insere precisamente na consideração "de uma determinada espécie animal", no caso o ser humano, "que só se desenvolve mediante um relativo grau de acerto, sobretudo mediante a regularidade de suas percepções (de maneira que possa capitalizar experiência)" (NIETZSCHE, 2002, p. 79) (grifos do autor). Com isso, o filósofo coloca o conhecimento ao mesmo tempo como produto e instrumento dos processos formativos da espécie humana. As forças instintuais constitutivas do humano, ou seja, os afetos, não apenas se autorregulam nas suas relações entre si, mas também na interação com o meio. Nesse sentido, Scarlett Marton afirma que uma vez "tendo em vista a fisiopsicologia nietzschiana" conceitos com alma, razão, entendimento etc, são ressignificados, de modo que se passa conceber que "todas as formas orgânicas tomam parte no pensar, no sentir e no querer, de sorte que o cérebro não passa de um enorme aparelho centralizador" (MARTON, 2014, p. 142).

Desse modo, Nietzsche afirma que ao considerarmos os processos gnosiológicos compete tomá-los "num sentido rigorosamente antropológico e biológico" (NIETZSCHE, 2002, p. 79). Isto significa dizer que, como afirmamos acima, o conhecer é uma atividade vital e ainda mais fundamentalmente, algo que só existe para a espécie humana por conter um especial valor evolutivo. Ou seja, para Nietzsche, o conhecimento se manteve enquanto perspectiva possível porque serviu para a manutenção da espécie humana. Para tanto, o filósofo defende o método por ele denominado de "morfologia da vontade de poder", ou simplesmente "genealogia"; e, com isso, como afirma Machado, "a análise do conhecimento em termos de forças que a genealogia realiza deve determinar se ele é a expressão de um excesso ou de uma indigência vital” (MACHADO, 2017, p. 81).

O que está em jogo para o filósofo não é mais a relação conhecimento-verdade, mas acima de tudo como o conhecimento se converte em um valor de caráter vital para a espécie humana. "A questão é em que medida ele promove ou conserva a vida", afirma o filósofo, e mais, se "conserva e até mesmo cultiva a espécie" (NIETZSCHE, 2005, p. 11). Seu proceder genealógico se voltaria assim não para "faculdades" intelectuais, mas para relações pulsionais. Com isso, as vivências (Erlebnisse) características do que denominamos conhecimento tem como condição um outro produto da evolução humana: a linguagem. Marton salienta que "são as palavras que possibilitam o tomar-consciência-de-si do pensamento" e, em última instância, encontra no aspecto gregário da espécie sua justificação, pois viabilizam sua 
socialização e reprodução (MARTON, 2014, p. 147). Em outras palavras, isto significa dizer que, para Nietzsche, diferentes relações entre as vontades de poder constituem diferentes formas de vida cujas necessidades de lidar com o meio impõem a criação da linguagem como forma de compartilhar as vivências comuns a maioria dos indivíduos da espécie.

Contudo, seria também o mesmo caráter gregário responsável pelas posturas dogmáticas em relação ao conhecimento, o que denota a permanência de uma mesma perspectiva: a do animal de rebanho. Em última análise, para Nietzsche, o que concebemos como conhecimento é o resultado do modo como as formas de vida mais precárias, cujas hierarquias pulsionais visavam unicamente a preservação — daí a ideia de conhecimento como algo fixo, imutável. O filósofo, como salienta Safranski, estende sua crítica ao conhecimento ao surgimento dos movimentos democráticos e socialistas de sua época, vistos como "consequências modernas da hipótese moral do cristianismo" (SAFRANSKI, 2017, p. 271) (grifos do autor). Nesse sentido, para Nietzsche, a Teoria do Conhecimento dos modernos teria sido responsável por validar uma avaliação moral específica: a concepção cristã de mundo. Nas palavras do filósofo, os modernos erraram por "sua falta de sentido histórico, seu ódio à noção mesma de vir-a-ser, seu egipcismo" (NIETZSCHE, 2017, p. 20).

Em contraposição a essa visão que nega a mudança e põe dúvida sobre o sentidos, esse apelo ao conhecimento verdadeiro, Nietzsche afirma que nossos "órgãos" gnosiológicos captam tão somente "as relações que constituem então entes, assim tampouco pode haver um ‘conhecimento em si'...” (NIETZSCHE, 2002, p. 80). Ou seja, para o filósofo conhecimento é perspectivo e condicionado às formas de vida. Mais que isso, ele deve se prestar sempre a elevação da espécie visto que a efetividade (Wirklichkeit) é um todo dinâmico e que a negação desse dinamismo culmina num processo de degenerescência que barra a ampliação dos horizontes pelos quais o ser humano se move. É nesse sentido, por exemplo, que ao analisar as posições assumidas pelos filósofos em relação a possibilidade do conhecimento, Hessen coloca Nietzsche entre os pragmáticos pois concebe o homem "antes de tudo, [como] um ser ativo" (HESSEN, 1978, p. 52). Em outros termos, como um ser criador.

À Teoria do Conhecimento, uma vez liberta do dogmatismo, caberia então a tarefa de investigar o conhecimento como uma maneira de "esquematizar, impor ao caos tanta regularidade e tantas formas quanto convier às nossas necessidades práticas" (NIETZSCHE, 2002, p. 96). E, nesse sentido, como se formaram e se fixaram, porque tornadas necessárias, as funções cognitivas que denominamos como razão, percepção, memória. Ou seja, cabe proceder genealogicamente em relação ao corpo humano e aos seus órgãos voltados para o 
conhecer - ou, nas palavras do filósofo, das funções orgânicas responsáveis em "subsumir, esquematizar para os fins do entendimento, do cálculo...” (NIETZSCHE, 2002, p. 96). E, desse modo, como lembra Machado, reconhecer que "existe uma diferença qualitativa entre os instintos" (MACHADO, 2017, p. 130). A seguir, veremos brevemente como isso ocorre com o uso da genealogia nietzschiana.

O corpo assume na filosofia nietzschiana um estatuto nunca antes conferido nenhum outro filósofo. Enquanto lugar onde se ordenam, se articulam e se processam as operações cognitivas, para Nietzsche, compete ao corpo "um privilégio metodológico, na medida em que fornece um fio condutor muito mais claro e distinto do que a mera introspecção" (MARTON, 2016, p. 160). Em Assim falou Zaratustra, o filósofo afirma "corpo sou eu inteiramente, e nada mais; e a alma é apenas uma palavra para algo no corpo" (NIETZSCHE, 2011, p. 3435). O corpo passa a ser então critério de objetividade de sua Erkenntnistheorie. Assim, por exemplo, diferentemente do que se evidencia na fisiologia cartesiana, para a qual o corpo seria uma espécie de "máquina orgânica" operando de forma peristáltica, responsável por guardar uma alma imortal de cuja essência, entretanto, seria distinto, para Nietzsche, por outro lado o corpo é concebido como a relação de múltiplas forças que opondo-se entre si lhe dão forma e sentido.

Em outras palavras, um corpo é "também uma multiplicidade de existências" selecionadas ao longo de gerações, sem nenhum plano preestabelecido, no jogo caótico das relações de forças, "que redundaram na utilidade de manter melhor o todo, tendo sido então mais bem desenvolvidos e mantidos. $\mathrm{O}$ crescimento conjugado de organismos, como meio de manter por mais tempo o ente individual" (NIETZSCHE, 2008, p. 158). O corpo, desse ponto de vista, é a um só tempo condição e consequência para e dos processos relativos ao acúmulo e uso de energias vitais. É por essa razão que Nietzsche compreende o corpo como "uma guerra e uma paz, um rebanho e um pastor" (NIETZSCHE, 2011, p. 35). Em outras palavras, as hierarquias estabelecidas pelos afetos, pelas forças constitutivas do corpo, consistem num equilíbrio paradoxal que só é possível na medida em que os afetos dominantes suportam os dominados e os últimos, por seu turno, oferecem resistência aos primeiros.

Se, por um lado os modernos, grosso modo, consideravam a razão como monolítica e nomotética, responsável por garantir o acesso ao que há de real, verdadeiro e, nesse sentido, contrária ao que é falso, ilusório. Por outro, pondo em ação o lado afirmativo de sua filosofia, Nietzsche salienta que é função da razão necessariamente "o adequar, o fazer com que se torne parecido, o igual — o mesmo processo pelo qual passa toda impressão sensória é o 
desenvolvimento da razão!” (NIETZSCHE, 2002, p. 96). Em outras palavras, contrariamente ao que defende (quase) toda a tradição ocidental, a razão sob o ponto de vista da Erkenntnistheorie nietzschiana seria justamente um órgão falseador. Considerando sua teoria da vontade de poder, é possível dizer que isto se dá, pois "agindo num elemento, a vontade de potência encontra obstáculos nos outros elementos que o circundam, mas tenta submeter os que a ele se opõem e colocá-los a seu serviço" (MARTON, 2014, p. 217). Ou seja, tornar possível um mundo em que existam permanência e regularidade, ainda que de forma ilusória, é algo próprio da perspectiva em que está instalada a espécie humana.

Selecionar, agrupar em categorias, ordenar segundo princípios, formular conceitos todas essas são as funções da razão, pois não existem enquanto propriedades dos fenômenos. Uma vez que a efetividade é múltipla e sempre mutável, cabe a esse órgão criar a falsa imagem de permanência, bem como a noção de identidade entre "entes", que se considerados pelas relações de forças que os constituem, diferem entre si. A razão suprime o caos do vir-aser. Ela é, por assim dizer, "uma espécie de estômago de todos os afetos (os quais querem ser nutridos)" (NIETZSCHE, 2008, p. 49). Reduzindo os dados da percepção a elementos mínimos que por sua vez servem ao aumento da capacidade do organismo em se relacionar e dominar o meio que o cerca. Nesse aspecto Nietzsche não se mostra tão diferente de Schopenhauer, por exemplo ${ }^{3}$.

À percepção cabe a concatenação arbitrária dos fenômenos ${ }^{4}$ uma vez que causa e efeito seriam invenções linguísticas para atender à necessidade de ordem imposta pela razão. Com isso, Nietzsche afirma que "tudo o que se torna consciente é um fenômeno final, uma conclusão - e não causa nada" (NIETZSCHE, 2002, p. 97), de modo que o fluxo das vivências repousa sobre um abismo que sequer é considerado nos estados conscientes o que aponta para dois níveis da percepção. Um mais raso e, portanto, de caráter gregário, passível de ser compartilhado e moldado socialmente; e outro mais profundo, no qual se encontram "as sensações em estado bruto que são interpretadas pelo intelecto por meio de assimilação" (MARTON, 2016, p. 374).

\footnotetext{
${ }^{3} \mathrm{O}$ que haveria de fundamentalmente distinto entre ambos nessa questão seria que, enquanto para Schopenhauer o conhecimento dos fenômenos estaria subordinado às formas a priori de tempo, espaço e causalidade, e nesse sentido, vetando o acesso do sujeito ao conhecimento de uma "coisa em si" que efetivamente existe e só é possível através da contemplação estética do gênio; para Nietzsche, a razão não é capaz de conhecê-la simplesmente porque esta é uma ilusão.

${ }^{4}$ Nietzsche realiza um passo atrás em relação a Kant e, nesse sentido, toma a ordem causal dos fenômenos como não necessária assim como Hume concebia, por exemplo.
} 
Nesse ponto se torna possível uma relação com Leibniz ${ }^{5}$, por exemplo, pois para este filósofo setecentista haveriam as "percepções inapercebidas", correspondentes a segunda classe de percepções para Nietzsche, e que estariam na base do processos de assimilação da experiência sensível e em permanente estado de latência. A diferença estaria precisamente no fato de que Nietzsche considera não haver "dúvida de que todas as percepções dos sentidos", ou seja, a primeira classe de percepções, "estão completamente impregnadas por juízos de valor (útil/prejudicial — portanto agradável ou desagradável)” (NIETZSCHE, 2002, p. 158) (grifos do autor) e, a partir daí, formular toda uma série de pares conceituais análogos como belo/feio, verdade/mentira, certo/errado. Nesse sentido elas seriam percepções das percepções, ou o que o filósofo chama de perspectivas.

Quanto a memória, considerada genealogicamente, seria uma questão concernente a necessidade de manutenção e retomada de certas vivências que em algum nível se mostraram capazes de se adequar aos esquemas conceituais produzidos pela razão e utilizados pela percepção em sua relação com a efetividade. Assim, para Nietzsche a "recordação tardia na medida em que o mesmo instinto equiparador aparece já como domado" (NIETZSCHE, 2002, p. 65) (grifo do autor). Metabolizando os dados da percepção, o organismo criaria condições para que os afetos correspondentes fossem fixados e com isso sempre retomados na medida em que fossem necessários. Nesse sentido o filósofo assinala o caráter ativo da memória enquanto órgão responsável não apenas por armazenar informações, mas principalmente por selecioná-las de acordo com as medidas de valor estabelecidas nas relações pulsionais a nível individual e coletivo.

O caráter gregário da espécie se afigura mais uma vez como fator preponderante para a formação dessa função gnosiológica. Tarefa empreendida pelo homem sobre si mesmo na medida em que, "requereu o auxílio de meios dolorosos, pois a proposição norteadora da mais antiga e ao mesmo tempo mais duradoura psicologia que houve foi aquela que viu na dor o melhor recurso da mnemônica" (MARTON, 2016, p. 299). A imediatez das vivências teria sido, com isso, progressivamente substituída por uma espécie de "soma de todas as vivências de toda vida orgânica, vívida, ordenando-se, formando-se reciprocamente, brigando umas com as outras, simplificando-se, condensando-se e transformando-se em muitas unidades"

\footnotetext{
${ }^{5} \mathrm{Na}$ Monadologia, Leibniz afirma "O estado passageiro, envolvendo e representando a multiplicidade na unidade ou na substância simples, é precisamente o que se chama Percepção, que deve distinguir-se da apercepção ou da consciência” §14. Ou seja, para o filósofo seiscentista, perceber é, grosso modo, reconhecer diferenças qualitativas/quantitativas. E mais adiante, reconhece que "há, porém, uma quantidade grande de pequenas percepções, e nestas nada distinto", §21. O que equivale a dizer que não se encontram ao nível da consciência, mas constituem parte dos "dados sensíveis" dos quais se torna possível toda percepção.
} 
(NIETZSCHE, 2008, p. 244). Em outras palavras, se tornando condição para a efetiva hominização da espécie humana.

Em resumo, é possível dizer que para Nietzsche o que está em jogo ao empreender a investigação genealógica acerca dos processos cognitivos, é que o conhecimento se presta não a obtenção da verdade, visto que ela seria apenas um valor; antes, o conhecimento desempenha uma função de aumento da capacidade de controle e manejo do meio em que o homem se encontra. Mais que isso, o filósofo demonstra que as "faculdades", outrora concebidas pelos filósofos como dadas, a priori por assim dizer, são igualmente constituídas a partir de um longo processo seletivo onde as pulsões que compõem o todo da vida humana tomaram formas específicas, se organizaram numa hierarquia dinâmica de relações de força. Nesse sentido, é possível dizer que ao pensar o conhecimento de um ponto de vista genealógico, Nietzsche radicaliza a Erkenntnistheorie.

Ademais, demonstra que ao negar pressupostos caros a tradição, o filósofo não incorre em um puro e simples irracionalismo, como muitas vezes é classificada a sua filosofia. Ao contrário, para Nietzsche o trabalho de negação é indissociável de uma atividade afirmativa onde o filósofo busca trabalhar questões tradicionalmente caras à Filosofia de uma perspectiva menos estanque, não dogmática e aberta a interpretações que levem o pensamento a ser testado e experimentado sempre. Tal como Losurdo salienta, em sua aversão aos movimentos revolucionários da Europa de então, nos quais o filósofo reconhece a herança do racionalismo cartesiano e sua concepção monolítica de sujeito, Nietzsche defende "o caráter inevitavelmente prospectivo do conhecimento visa também à desconstrução da categoria de universalidade" (LOSURDO, 2016, p. 53). Pois assim como não o filósofo compreende que não pode haver o sujeito unitário, igual entre iguais, defendido pelos movimentos democráticos, por exemplo, também não pode haver conhecimento universal. À guisa de conclusão, observamos que uma crítica nietzschiana do conhecimento se torna possível através de sua genealogia. Nesse sentido, o método genealógico seria então responsável por investigar as condições de possibilidade de constituição das instâncias avaliativas através das quais o ser humano se orienta e se relaciona com o meio.

\section{REFERÊNCIAS BIBLIOGRÁFICAS}

HESSEN, Johannes. Teoria do Conhecimento. 7 ed. Tradução Antônio Correia. Coimbra, Armênio Amado, 1978. 
LEIBNIZ, Gottfried Wilhelm. A monadologia. Traduções de Carlos Lopes de Matos era al. São Paulo, Abril Cultural, 1983. (Os pensadores)

LOSURDO, Domenico. Nietzsche e a crítica da Modernidade. Tradução Alessandra Siedschlag. São Paulo, Ideias e Letras, 2016. (Série Pensamento Dinâmico)

MACHADOO, Roberto. Nietzsche e a verdade. 3 ed. Rio de Janeiro/São Paulo, Paz e Terra, 2017.

MARTON, Scarlett. (org.) Dicionário Nietzsche. São Paulo, Edições Loyola, 2016.

MARTON, Scarlett. Nietzsche e a arte de decifrar enigmas. Treze conferências europeias. 1 ed. São Paulo, Edições Loyola, 2014. (Coleção Sendas \& Veredas)

NIETZSCHE, Friedrich Wilhelm. Além do bem e do mal: prelúdio a uma filosofia do futuro. Tradução, notas e posfácio Paulo César de Souza. São Paulo, Companhia das Letras, 2005.

NIETZSCHE, Friedrich Wilhelm. Assim falou Zaratustra: um livro para todos e para ninguém. Tradução, notas e posfácio Paulo César de Souza. São Paulo, Companhia das Letras, 2011.

NIETZSCHE, Friedrich Wilhelm. Crepúsculo dos ídolos, ou como se filosofa com o martelo. Tradução, notas e posfácio Paulo César de Souza. São Paulo, Companhia de Bolso, 2017.

NIETZSCHE, Friedrich Wilhelm. Fragmentos do espólio: primavera de 1884 a outono de 1885. Seleção, tradução e prefácio de Flávio R. Kothe. Brasília, Editora Universidade de Brasília, 2008.

NIETZSCHE, Friedrich Wilhelm. Fragmentos finais. Seleção, tradução e prefácio de Flávio R. Kothe. Brasília, Editora Universidade de Brasília; São Paulo, Imprensa Oficial do Estado, 2002.

NUNES, Benedito. Filosofia contemporânea. Belém, EDUFPA, 2004.

SAFRANSKI, Rüdiger. Nietzsche: biografia de uma tragédia. Tradução Lua Luft. São Paulo, Geração Editorial, 2017.

Artigo recebido em:06/11/20

Artigo aprovado em:13/12/20 